\title{
Comparative Analysis of Pinewood, Peanut Shell, and Bamboo Biomass Derived Biochars Produced via Hydrothermal Conversion and Pyrolysis
}

\author{
Matthew D. Huff, ${ }^{1}$ Sandeep Kumar, ${ }^{2}$ James W. Lee ${ }^{1 *}$ \\ ${ }^{1}$ Department of Chemistry and Biochemistry and ${ }^{2}$ Department of Civil and Environmental \\ Engineering, \\ Old Dominion University, Norfolk, VA 23529 \\ *Corresponding Author Email: jwlee@odu.edu
}

\section{Research Highlights}

- A series of biochar materials for comparative study were produced from pinewood, peanut shell, and bamboo biomass through hydrothermal conversion at $300{ }^{\circ} \mathrm{C}$ and by slow pyrolysis at 300,400 , and $500{ }^{\circ} \mathrm{C}$.

- The experiments demonstrated higher cation exchange capacity in biochars produced at lower pyrolysis temperatures and through hydrothermal conversion.

- All types of biochar studied herein were capable of adsorption of methylene blue from solution and the adsorption did not appear to strongly correlate with cation exchange capacity.

- Analysis by FT-IR reveals a higher retention of oxygen functional groups in hydrothermalproduced biochars.

- Biochar cation exchange capacity appears correlated with its oxygen functional group content.

\begin{abstract}
Biochars were produced from pinewood, peanut shell, and bamboo biomass through hydrothermal conversion (HTC) at $300{ }^{\circ} \mathrm{C}$ and comparatively by slow pyrolysis over a temperature range of 300,400 , and $500{ }^{\circ} \mathrm{C}$. These biochars were characterized by FT-IR, cation exchange capacity (CEC) assay, methylene blue adsorption, as well as proximate and elemental analysis. The experimental results demonstrated higher retained oxygen content in biochars produced at lower pyrolysis temperatures and through HTC, which also correlated to the higher
\end{abstract}


CEC of respective biochars. Furthermore, all types of biochar studied herein were capable of adsorption of methylene blue from solution and the adsorption did not appear to strongly correlate with CEC, indicating that the methylene blue adsorption appears to be dependent more upon the non-electrostatic molecular interactions such as the likely dispersive $\pi$ - $\pi$ interactions between the graphene-like sheets of the biochar with the aromatic ring structure of the dye, than the electrostatic CEC. A direct comparison of hydrothermal and pyrolysis converted biochars reveals that biochars produced through HTC have much higher CEC than the biochars produced by slow pyrolysis. Analysis by FT-IR reveals a higher retention of oxygen functional groups in HTC biochars; additionally, there is an apparent trend of increasing aromaticity of the pyrolysis biochars when produced at higher temperatures. The CEC value of the HTC biochar appears correlated with its oxygen functional group content as indicated by the FT-IR measurements and its $\mathrm{O}: \mathrm{C}$ ratio.

Keywords: Soil carbon sequestration, slow pyrolysis, hydrothermal conversion, biochar, cation exchange capacity

\section{- Introduction}

The conversion of biomass into biochar by either pyrolysis or hydrothermal conversion has been illustrated to be an important potential tool for both carbon sequestration and soil amendment (l). Pyrolysis of biomass is usually divided into three main categories: slow pyrolysis, fast pyrolysis, and gasification. Slow pyrolysis is a more traditional means for the production of biochar, and involves the heating of biomass in the absence of oxygen over relatively long periods $(\geq 30$ 
minutes) of time at atmospheric pressure. Fast pyrolysis usually occurs on the order of a few seconds or minutes. Slow and fast pyrolysis can be implemented in many different types of reactors, some of the most used of these reactors being batch or auger type. Gasification of biomass is carried out at much higher temperatures $\left(>700{ }^{\circ} \mathrm{C}\right)$ and is used to primarily to produce syngas and bio-oil. Hydrothermal conversion (HTC) is the practice of placing suitable biomass into a sealed vessel with water as a reaction medium, and then heating the vessel at low to moderate $\left(200-300{ }^{\circ} \mathrm{C}\right)$ temperatures $(2,3)$. Although the process has been known for close to a century, much interest has recently been paid to HTC as an efficient method for biomass conversion (4). Further research in HTC has been driven by the usefulness of the converted products, namely the use of biochar as a sorbent for toxic materials such as heavy metals $(5,6)$. Additionally, HTC as well as pyrolysis of biomass materials produce a bio-oil byproduct which can potentially be utilized as fuel $(7,8)$. The biomass is converted, under autogenic pressures, into biochar, a solid carbon-rich product. Both methods of synthesis take biomass which has a naturally relatively short lifetime and convert it to a carbon rich solid which has been shown to be stable over hundreds of years $(9,10,11)$. In choosing a biochar for soil amendment properties, and/or as a carbon sequestration agent, it is important to look at the characteristics pertinent to the desired application. One of the most important features when considering the use of biochar as soil amendment is its cation exchange capacity (CEC). Biochar with high CEC values are much more desirable in soils, as the biochar will allow for greater retention and availability of cations such as $\mathrm{NH}_{4}{ }^{+}$and $\mathrm{K}^{+}(12)$. As far as carbon sequestration is concerned, long term stability in soil is of major consideration. Attributes of biochar such as its fixed carbon content (percentage) and $\mathrm{O}: \mathrm{C}$ ratio can serve as important factors in assessing the stability of these products on a long term basis $(13,14,15)$. 
The biomasses utilized in this study were pinewood, peanut shell, and bamboo.

Pinewood and bamboo biomasses were chosen for reasons similar to those previously reported, in that wood residues make up for $39 \%$ of the total biomass available in the United States (16). Additionally, the U. S. produces a large amount of peanuts annually, and given that peanut shells are a natural by-product of this process, it is important to look for ways to use this biomass beneficially.

Although biochar production by biomass pyrolysis has been quite wells studied, reports on biochar production through HTC are relatively fewer $(4,5,8)$. HTC of biomass into biochar could potentially be one of the potential technology options to achieve a "smokeless" biochar and biofuel production process, which would be desirable to minimize the potential impact on environmental air quality, especially in considering the envisioned biochar carbon sequestration at giga-tons-carbon $(\mathrm{GtC})$ scales to control global climate change. It is essential to further understand the characteristics of biochars produced by HTC and pyrolysis from various feedstocks of biomass materials. In this paper, we report a comparative HTC vs. pyrolysis biochar production study in relation to the potential use of biochars as a beneficial soil amendment and potential carbon sequestration agent.

\section{- Materials and Methods}

The types of biomass used in this study included pinewood, peanut shell, and bamboo, all of them were provided by Danny Day of Eprida Inc. The pinewood and peanut shell biomasses were in a pelletized form, while the bamboo biomass consisted of 1-2 cm long slivers. After 
receiving these biomass samples, all of them were dried at $70{ }^{\circ} \mathrm{C}$ in an electric oven for 48 hours before use for biochar production study.

Biomass was converted into biochar by pyrolysis or HTC using the same $500-\mathrm{mL}$ hastelloy autoclave high-pressure batch reactor (Parr reactor) system equipped with proportionalintegral-differential controllers (17). Pyrolysis was carried out on each type of biomass at 300, 400 , and $500{ }^{\circ} \mathrm{C}$, respectively, using $\mathrm{N}_{2}$ as a sweep gas. Heating of the reactor was carried out at a rate of $12{ }^{\circ} \mathrm{C}$ per min, and the highest treatment temperature (HTT) was held for 30 minutes during each trial. Biochars produced via pyrolysis were then collected after cooling the reactor to the room temperature and weighed directly to determine yield.

HTC was performed by placing biomass and water with a 1:3 mass ratio into the reactor. The reactor was then sealed and heated to $300{ }^{\circ} \mathrm{C}$ at a rate of $8{ }^{\circ} \mathrm{C} \mathrm{min}{ }^{-1}$ and held at autogenic pressure conditions for 30 minutes. Once the reaction time was completed, the reactor was rapidly cooled utilizing an internal water coil. The biochars made via HTC were then removed from the reactor, filtered, and then dried overnight at $105{ }^{\circ} \mathrm{C}$. The dried samples were then weighed to determine yield.

\section{- Products Analyses}

pH determination. The $\mathrm{pH}$ of each type of biochar was measured by first taking a $20 \mathrm{~g}$ aliquot of biochar and suspending it in $80 \mathrm{~mL}$ of millipore water in $125 \mathrm{~mL}$ Erlenmeyer flasks. The samples were then shaken at $100 \mathrm{rpm}$ for $48 \mathrm{~h}$. The $\mathrm{pH}$ of the resulting biochar/water slurry was then recorded. 
Elemental Analysis. Representative samples of biochars produced from pinewood via pyrolysis at 300,400 , and $500{ }^{\circ} \mathrm{C}$ and via HTC were sent to the Galbraith Laboratories in Knoxville, TN, for proximate and elemental $(\mathrm{C}, \mathrm{H}$, and $\mathrm{N})$ analysis.

Reference Soil Sample. The reference soil sample was provided by Dr. Charles Garten of Oak Ridge National Laboratory. This soil sample was collected from a surface soil of 0-15 cm deep at the University of Tennessee's Research and Education Center, Milan, TN (358560N latitude, 888430W longitude), which is also known as the Carbon Sequestration in Terrestrial Ecosystems site (CSiTE) supported by the US Department of Energy. The soil sample was autoclaved at $120{ }^{\circ} \mathrm{C}$ for $30 \mathrm{~min}$ prior to shipping and use in this study. Additional information pertaining to the soil sample is reported in reference (18).

Cation exchange capacity measurement. CEC refers to the number of exchangeable cations located on the surface of a given sample. The method of measurement utilized herein was that of compulsive barium loading, wherein barium is used in high concentration to essentially displace all other cation species on the surface of the biochar. The barium itself is then displaced via magnesium ions as well as competing protons during the assay, and the resultant $\mathrm{CEC}$ is measured by the change in the conductivity of the CEC assay medium. CEC measurement was carried out using a procedure modified from the method reported in Ref. 18 and 19. Initially, all CEC measurements were carried out at a $\mathrm{pH} 8.5$ and subsequently the $\mathrm{pH}$ was adjusted using $0.010 \mathrm{M} \mathrm{H}_{2} \mathrm{SO}_{4}$ by half units until a final $\mathrm{pH}$ of 5.0 was reached. At each half point $\mathrm{pH}$ unit, successive CEC measurements were taken. The detailed procedure for CEC measurement is given in the supporting information. 
Methylene Blue Adsorption Assay. Methylene blue adsorption assays were performed in order to measure the interaction of biochar with a charged organic compound. These assays were performed using a modified procedure based on protocols published (20). Standard amounts (50 $\mathrm{mg}$ ) of previously ground biochar were placed into 50mL centrifuge tubes. To each biochar

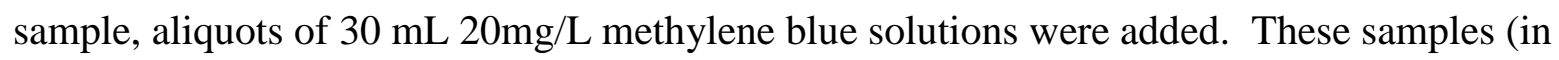
$50 \mathrm{~mL}$ centrifuge tubes) were then placed onto an Innova 2300 platform shaker, and shaken at $100 \mathrm{rpm}$ at room temperature for $48 \mathrm{~h}$. After the allotted time, the samples were then centrifuged at 20,000 (48,384 xG) rpm for $10 \mathrm{~min}$ in order to pelletize any particulate. Aqueous portions of the samples were then placed into quartz cuvettes and UV-Visible measurements were taken with a Cary 5000 spectrophotometer at $665 \mathrm{~nm}$. Each sample was taken in duplicate in order to reduce error in measurement. The concentration of remaining methylene blue in solution was measured by process outlined in reference (20). Average results $(n=2)$ are reported.

$$
Q e=\frac{(\mathrm{Co}-\mathrm{Ce}) \mathrm{V}}{W}
$$

Wherein, $\mathrm{Q}_{\mathrm{e}}$ is the amount of methylene blue removed from solution as reported in $\mathrm{mg} / \mathrm{g}$ biochar added, $\mathrm{C}_{\mathrm{o}}$ and $\mathrm{C}_{\mathrm{e}}$ are the initial and equilibrium concentrations $(\mathrm{g} / \mathrm{L})$, respectively, $\mathrm{V}$ is the volume of solution used, and $\mathrm{W}$ is the grams of biochar used.

IR-Spectroscopy. Infrared spectra were obtained with a Shimadzu IRPrestige-21 FT-IR spectrophotometer. Samples were placed into an ATR attachment utilizing a ZnSe trough. Spectra were collected over 256 scans, at a resolution of $4 \mathrm{~cm}^{-1}$, and over a range of 750-4000 $\mathrm{cm}^{-1}$. 


\section{- Results and Discussion}

Biomass Conversion Efficiencies. Table 1 reports the yield of each type of biochar either via pyrolysis or HTC calculated from the input dry weight of the biomass. As expected, biochar yield decreased with higher treatment temperatures. This is due to greater volatilization which converts a greater amount of biomass to bio-oil and gaseous products (21). The hydrothermally converted biomass shows the greatest percentage of biochar synthesized, which is also expected due to the higher pressures involved, which naturally favor the formation and retention of solid products (22).

Table 1. Percentage yield of biochar as a function of temperature, biomass, and process method.

\begin{tabular}{|lcccc|}
\hline Temperature $^{\circ} \mathbf{C}$ & $\mathbf{3 0 0}$ & $\mathbf{4 0 0}$ & $\mathbf{5 0 0}$ & $\mathbf{3 0 0}$ \\
\hline Process method & Pyrolysis & Pyrolysis & Pyrolysis & HTC \\
\hline Pine & $32.89 \pm 0.22$ & $27.26 \pm 0$ & $26.47 \pm 0.08$ & 49.51 \\
\hline Peanut & $38.64 \pm 1.12$ & $33.64 \pm 0.29$ & $32.01 \pm 0.13$ & 50.07 \\
\hline Bamboo & $33.25 \pm 0.84$ & $29.93 \pm 0.21$ & $28.75 \pm 0.24$ & 32.73 \\
\hline
\end{tabular}

The $\mathrm{pH}$ of each type of biochar differed mainly on the basis on the type of synthesis, as shown in Figure 1. It is well known that the reaction pathway via pyrolysis yields alkaline biochar (23), while the reaction pathway of HTC yields an acidic biochar (24). Higher treatment temperatures yielded higher $\mathrm{pH}$ values when concerning biochars produced via pyrolysis. 


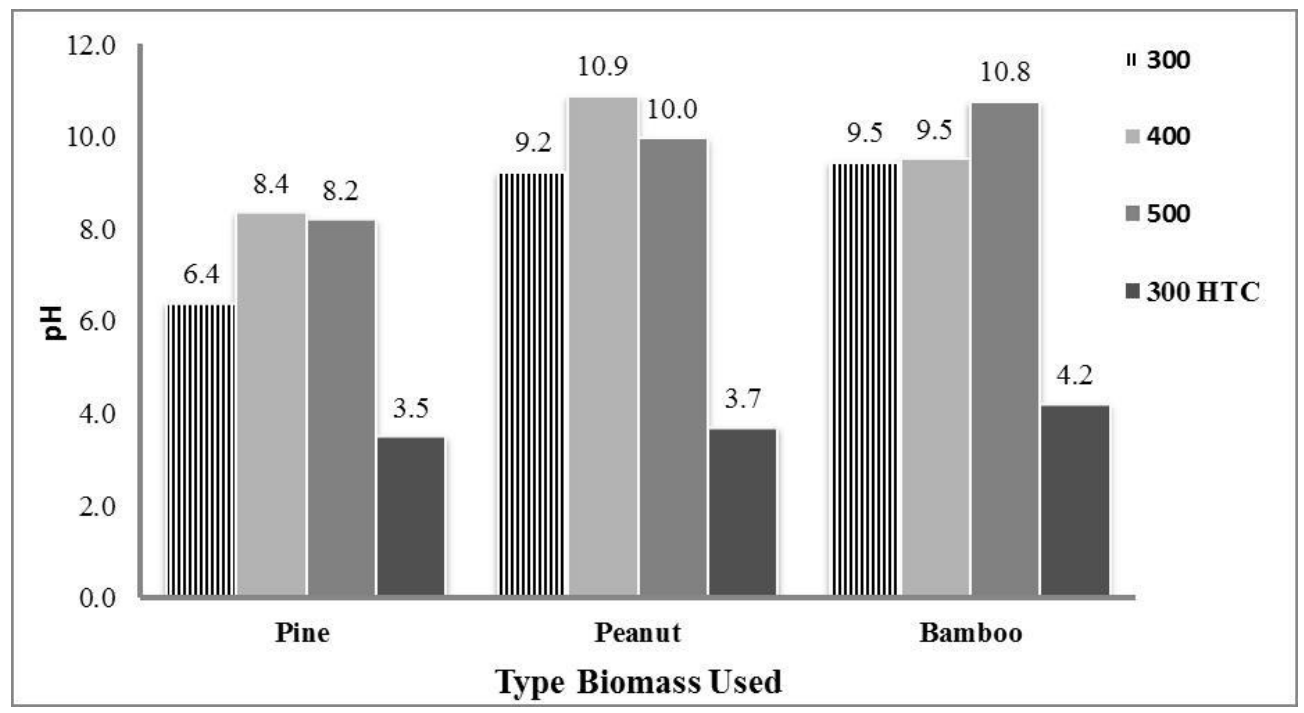

Fig. 1. pH of biochars as a function of temperature, and types of biomass.

Biochar FT-IR Analyses. FT-IR measurements revealed the biochar functional group differences in relation to the biomass thermal conversion processes. As shown in Figure 2, peaks about 1100,1200 , and $1670 \mathrm{~cm}^{-1}$ appear in the HTC biochars, but not in biochars produced via pyrolysis. The peaks at $\sim 1100$ and $1200 \mathrm{~cm}^{-1}$ correspond to $\mathrm{C}-\mathrm{O}$ stretching and $\mathrm{O}-\mathrm{H}$ bending modes of alcoholic, phenolic, and carboxylic groups (25). The peak at $1670 \mathrm{~cm}^{-1}$ is indicative of $\mathrm{C}=\mathrm{O}$ stretching. All samples exhibit a peak at $1570 \mathrm{~cm}^{-1}$, corresponding to $\mathrm{C}=\mathrm{C}$ stretching, which is representative of the aromatic nature of the samples. Additionally, concerning the biochar samples produced via pyrolysis, there is a temperature dependence on the relative intensity of the peak at $1570 \mathrm{~cm}^{-1}$, which indicates a greater amount of $\mathrm{C}=\mathrm{C}$ bonds being formed as the HTT is increased. Also, an intense peak at $870 \mathrm{~cm}^{-1}$ found samples produced via pyrolysis can be attributed to aromatic C-H bending (26). Overall, the FT-IR spectra exhibit a higher retained amount of oxygen functional groups for HTC biochars, as well as a higher degree of aromatic functionality for biochars produced via pyrolysis. 


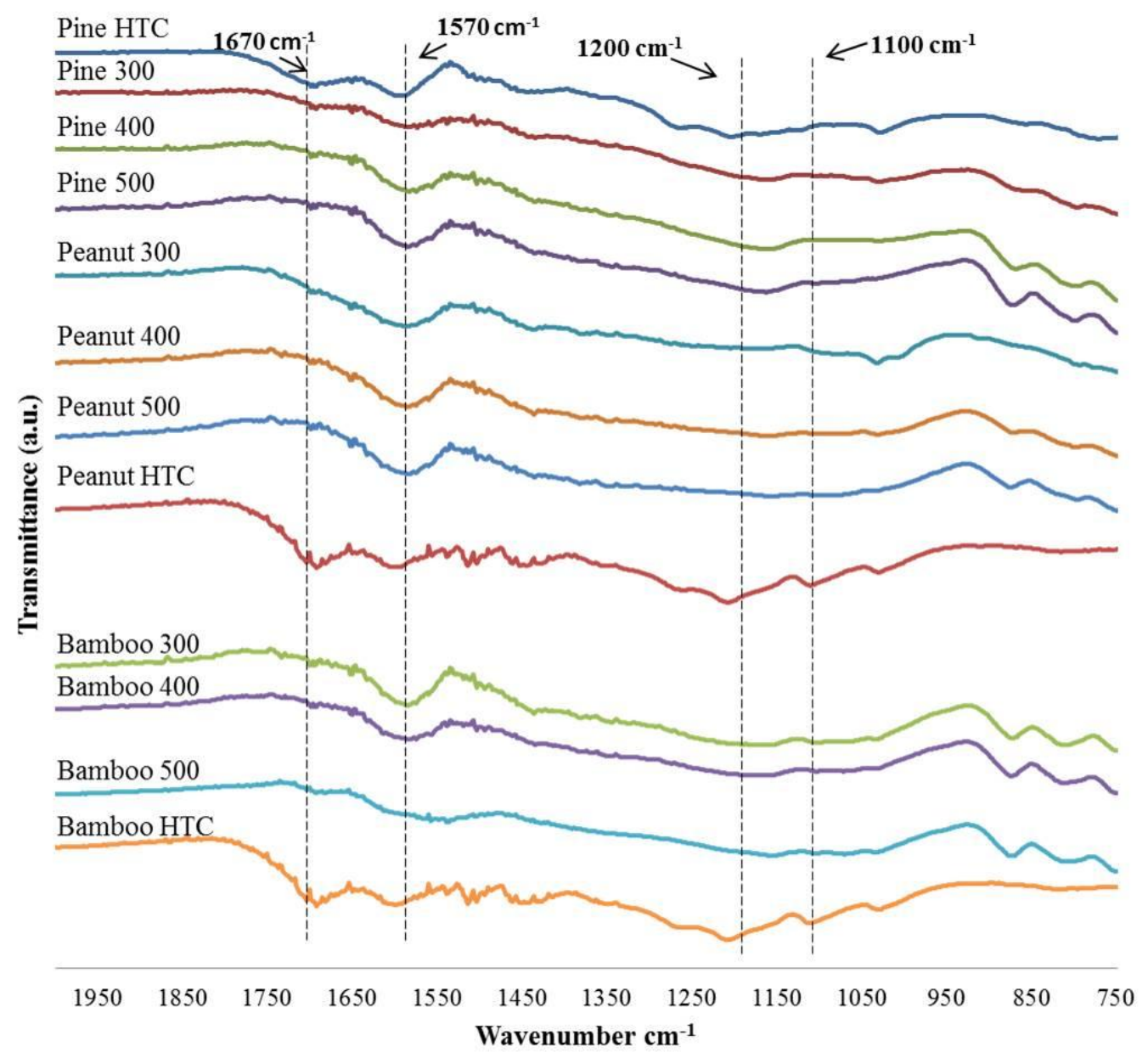

Fig. 2. FT-IR spectra of biochar samples.

Proximate and Elemental Analysis. Proximate analysis revealed a temperature dependence of volatile matter content for pine biochars produced via pyrolysis. Pine biochars were chosen as representative samples for proximate/elemental analysis. As Table 2 shows, as temperature was increased, volatile matter content decreased substantially $(27.89 \%, 19.57 \%$, and $11.67 \%$ for the biochars produced via pyrolysis at 300,400 , and $500{ }^{\circ} \mathrm{C}$, respectively). By comparison, the biochar produced from pinewood via HTC retains a relatively high amount of volatile matter (46.72\%). Furthermore, a similar pattern is seen in fixed carbon content, for biochars produced 
via pyrolysis in that increased temperatures yielded a biochar with higher fixed carbon percentages especially when comparing that of biochar produced at $300{ }^{\circ} \mathrm{C}(67.18 \%)$, to those produced at 400 and $500{ }^{\circ} \mathrm{C}(76.44 \%$ and $82.11 \%$ fixed carbon, respectively). The HTC biochar shows a much lower fixed carbon (50.8\%), which is consistent with its relatively high amount of volatile matter $(46.72 \%)$. Ash content percentages show a dependence on temperature for pine biochars produced via pyrolysis, $4.93 \%, 3.99 \%$, and $2.37 \%$ for samples produced at 300, 400 and $500{ }^{\circ} \mathrm{C}$, respectively. Pine HTC biochar has nearly the same value (2.39\%) for ash content as the biochar produced by pyrolysis at $500{ }^{\circ} \mathrm{C}$. The elemental analysis shows that a loss of oxygen atoms at higher temperatures, as well as a higher amount of oxygen retained for the biochar produced via HTC. This is correlated by the FT-IR spectra in which the peak at $1640 \mathrm{~cm}^{-1}$ appears more intense in the HTC biochar, and much weaker in the biochars produced by pyrolysis, especially at higher treatment temperatures. Oxygen content was calculated by analysis, rather than by difference. The O:C mol ratio gives some idea as to the long term stability of biochar in soil (20), wherein the higher the ratio, the less stable the biochar. Typically, biochars with an O:C 0.2 or greater have half lives in soil of 100-1000 years, while biochars with O:C lower than 0.2 have half lives in soil greater than 1000 years (27). The results of this analysis show that all pine biochars produced via pyrolysis are placed into the latter category, while the pine biochar produced via HTC belongs in the former category.

Table 2. Biochar Elemental and Proximate Analysis.

\begin{tabular}{|c|c|c|c|c|c|c|c|c|c|}
\hline Sample & $\begin{array}{c}\% \text { loss on } \\
\text { drying }\end{array}$ & $\begin{array}{c}\% \text { volatile } \\
\text { matter }\end{array}$ & $\%$ Ash & $\begin{array}{l}\text { \% fixed carbon } \\
\text { (by difference) }\end{array}$ & $\mathrm{C} \%$ & H\% & N\% & $\mathbf{0 \%}$ & $\begin{array}{c}\text { O:C (mol } \\
\text { ratio) }\end{array}$ \\
\hline Pine 300 & 4.08 & 27.89 & 4.93 & 67.18 & 74.17 & 3.76 & $<0.5$ & 14.54 & 0.15 \\
\hline Pine 400 & 4.88 & 19.57 & 3.99 & 76.44 & 81.64 & 2.69 & $<0.5$ & 5.26 & 0.05 \\
\hline Pine 500 & 4.29 & 11.67 & 2.37 & 82.11 & 83.2 & 2.74 & $<0.5$ & 4.05 & 0.036 \\
\hline Pine HTC & 3.71 & 46.72 & 2.39 & 50.8 & 66.45 & 4.2 & $<0.5$ & 22.84 & 0.26 \\
\hline
\end{tabular}


CEC of Biochar Samples. CEC was shown to be dependent on production process, highest treatment temperature, and biomass precursor. This assay allows for the comparison of biochar samples over a range of $\mathrm{pH}$ values, which is important due to the varying native $\mathrm{pH}$ of the samples, especially when comparing pyrolysis biochar samples with HTC biochar samples. The greatest impact upon CEC is shown by the comparison of HTC biochar versus that of biochars produced via pyrolysis. At $\mathrm{pH} 8.5$, pine biochars produced at 300,400 and $500{ }^{\circ} \mathrm{C}$ show CEC values of $13.474 \pm 1.385 \mathrm{cmol} \mathrm{Kg}^{-1}, 8.991 \pm 1.457 \mathrm{cmol} \mathrm{Kg}^{-1}$, and $5.786 \pm 3.620 \mathrm{cmol} \mathrm{Kg}^{-1}$, respectively. Comparatively, HTC biochar has a CEC of $63.465 \pm 3.658 \mathrm{cmol} \mathrm{Kg}^{-1}$ at $\mathrm{pH} 8.5$. A similar trend was observed for peanut and bamboo biochars. By comparison, the CEC of the reference soil at $\mathrm{pH} 8.5$ was $16.174 \pm 1.215 \mathrm{cmol} \mathrm{Kg}^{-1}$. As shown in Figure 3, the HTC biochars resulted in the greatest CEC value when compared to the biochars converted via pyrolysis. The complete set of CEC data values measured for all 12 biochar samples and the reference soil through these assays can be found in Table S1 of the Supporting Information. 


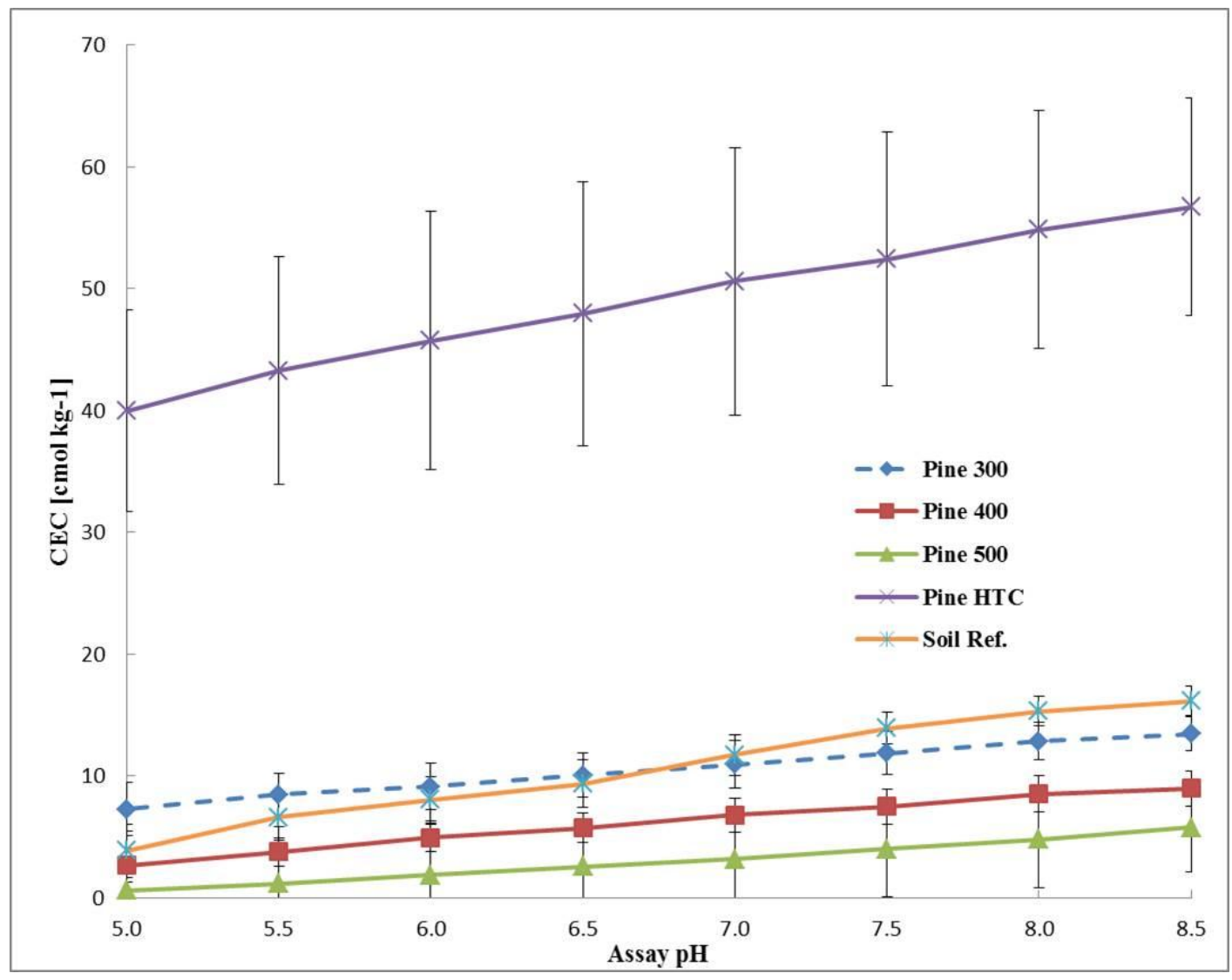

Fig. 3. CEC of biochars derived from pinewood biomass and soil reference sample.

In comparing biochars produced via pyrolysis at different pyrolysis temperatures, there is a clear relationship between HTT and CEC, that being the lower the temperature, the higher the CEC. This correlates with the loss of oxygen functional groups as measured by FT-IR over increasing HTT. This data also corresponds well with the O:C mol ratio as determined by elemental analysis. Retained oxygen content correlates with higher CEC values, as shown in Figure 4. All biochar CEC assays show a dependence on $\mathrm{pH}$. At lower $\mathrm{pH}$ values, protons compete with bound cations on the biochar surface, thereby driving the cations off the sample surface and into solution. 


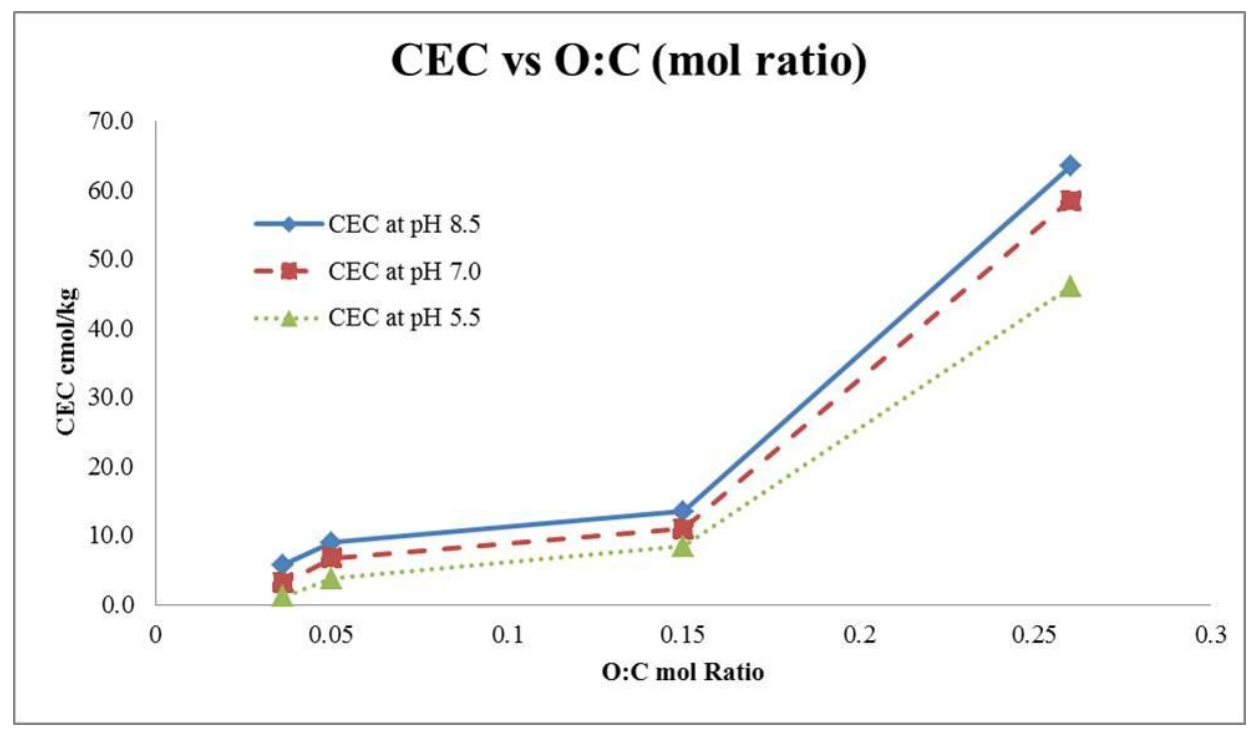

Fig. 4. CEC of pinewood-derived biochar samples as a function of O:C mol ratio for a range of $\mathrm{pH}$ values.

Methylene blue adsorption. The observed methylene blue adsorption results show that there is greater affinity for methylene blue onto biochars produced via pyrolysis at $300{ }^{\circ} \mathrm{C}$ as compared to biochars produced at 400 and $500{ }^{\circ} \mathrm{C}$. Furthermore, the results indicate a greater correlation as to which biomass precursor was used over synthetic route used. There seems to be no clear correlation between biochar's CEC and methylene blue adsorption. Previously published results suggest that the mechanism for dye adsorption onto biochar is dependent on dispersive $\pi-\pi$ interactions between the graphene-like sheets of the biochar with the aromatic ring structure of the dye (28). As shown in Figure S1 of the supporting information, the molecular structure of methylene blue contains a type of aromatic ring structure in addition to the positively charged amine group (cation). Pine biochars produced via pyrolysis showed the lowest methylene blue adsorption at an average range of $1.1\left(300{ }^{\circ} \mathrm{C}\right)-2.5\left(500{ }^{\circ} \mathrm{C}\right) \mathrm{mg} / \mathrm{g}$ of biochar, while peanut biochars produced by pyrolysis show the highest amount of adsorbed methylene blue, ranging on 
average from $3.7\left(300{ }^{\circ} \mathrm{C}\right)-6.7\left(500{ }^{\circ} \mathrm{C}\right) \mathrm{mg} / \mathrm{g}$ of biochar. The pine biochar produced by HTC shows the highest amount of adsorbed methylene blue $(5.8 \mathrm{mg} / \mathrm{g}$ of biochar) when compared to the $3.5 \mathrm{mg} / \mathrm{g}$ and $4.6 \mathrm{mg} / \mathrm{g}$ for the HTC peanut and bamboo biochars.

Table 3. Methylene blue adsorption onto biochar samples (units of mg of methylene blue removed/ $\mathrm{g}$ biochar, results in duplicate).

\begin{tabular}{|lcccc|}
\hline Temperature $^{\circ} \mathbf{C}$ & $\mathbf{3 0 0}$ & $\mathbf{4 0 0}$ & $\mathbf{5 0 0}$ & $\mathbf{3 0 0}$ \\
\hline Process method & Pyrolysis & Pyrolysis & Pyrolysis & HTC \\
\hline Pine & $2.54 \pm 0.966$ & $1.82 \pm 0.214$ & $1.16 \pm 0.494$ & $5.81 \pm 0.092$ \\
\hline Peanut & $6.76 \pm 0.006$ & $5.22 \pm 0.264$ & $3.69 \pm 0.408$ & $3.51 \pm 1.288$ \\
\hline Bamboo & $4.78 \pm 0.148$ & $3.58 \pm 0.176$ & $3.88 \pm 0.138$ & $4.67 \pm 0.987$ \\
\hline
\end{tabular}

\section{Conclusions}

All biochars produced by HTC had CEC values higher than that of the soil reference, as well as did peanut shell and bamboo biochars produced by pyrolysis at $300{ }^{\circ} \mathrm{C}$ and bamboo at $400{ }^{\circ} \mathrm{C}$. The $\mathrm{CEC}$ value of the HTC biochar appears correlated with its oxygen functional group content as indicated by its O:C ratio and the FT-IR results. In addition, all biochars produced also show some affinity for the removal of methylene blue from solution, although it appears that the type of biomass used, rather than process treatment dictates the effectiveness of adsorption of methylene blue from solution. These results indicate the possibility of the use of these biochars for the potential removal of certain organic molecules such as dyes in water. As shown by proximate analysis, much higher fixed carbon content is created in biochars produced by pyrolysis, and is a function of highest treatment temperature as noted by previous reports ( 21 , 
29). Percent volatile matter follows the same trend as fixed carbon content as well. Quite interestingly, biochars produced by HTC tend to retain much higher oxygen content when compared with biochar produced from the same biomass via pyrolysis. CEC values for biochars produced by HTC were much higher when compared with biochars produced via pyrolysis, a trend that fits well with the $\mathrm{O}: \mathrm{C}$ ratio. Future studies to comparatively analyze the potential biochar toxin content in these biochar materials will help to determine their viability for use as soil amendments.

\section{- Acknowledgments}

We thank Mr. Danny Day for providing the biomass samples including pinewood, peanut shells, and bamboo, and Dr. Charles Garten of U.S. DOE Oak Ridge National Laboratory for providing the reference soil sample used in this study. This research was supported, in part, by the 2013 Old Dominion University Multidisciplinary Seed Funding Program, and by Dr. Lee's start-up research funds provided by the Department of Chemistry and Biochemistry, the College of Sciences, the Office of Research at ODU, and the ODU Research Foundation. The authors would also like to extend our thanks to Dr. Richard Gregory and Thomas Sprinkle, Applied Research Center at Old Dominion for their assistance in obtaining FT-IR spectra.

\section{- Supporting Information Available}

Supporting information includes (1) the chemical structure of methylene blue; and (2) the full method and data table for CEC of all samples over a $\mathrm{pH}$ range of 8.5 to 5 . This material is available free of charge via the Internet at http://pubs.acs.org. 


\section{- Literature Cited}

1. Day, D.; Evans, R. J.; Lee, J. W.; Reicosky, D., Economical $\mathrm{CO}_{2}$, SOx, and NOx capture from fossil-fuel utilization with combined renewable hydrogen production and largescale carbon sequestration. Energy-the International Journal 2005, 30, (14), 2558-2579.

2. Sevilla, M.; Maciá-Agulló, J. A.; Fuertes, A. B., Hydrothermal carbonization of biomass as a route for the sequestration of $\mathrm{CO} 2$ : Chemical and structural properties of the carbonized products. Biomass and Bioenergy 2011, 35, (7), 3152-3159.

3. Titirici, M.-M.; White, R. J.; Falco, C.; Sevilla, M., Black perspectives for a green future: hydrothermal carbons for environment protection and energy storage. Energy \& Environmental Science 2012, 5, (5), 6796-6822.

4. Funke, A.; Ziegler, F., Hydrothermal carbonization of biomass: A summary and discussion of chemical mechanisms for process engineering. Biofuels, Bioproducts and Biorefining 2010, 4, (2), 160-177.

5. Hu, B.; Wang, K.; Wu, L.; Yu, S.-H.; Antonietti, M.; Titirici, M.-M., Engineering Carbon Materials from the Hydrothermal Carbonization Process of Biomass. Advanced Materials 2010, 22, (7), 813-828.

6. Kumar, S.; Loganathan, V. A.; Gupta, R. B.; Barnett, M. O., An Assessment of U(VI) removal from groundwater using biochar produced from hydrothermal carbonization. Journal of Environmental Management 2011, 92, (10), 2504-2512.

7. Mohan, D.; Pittman, C. U.; Steele, P. H., Pyrolysis of Wood/Biomass for Bio-oil: A Critical Review. Energy \& Fuels 2006, 20, (3), 848-889.

8. Akhtar, J.; Amin, N. A. S., A review on process conditions for optimum bio-oil yield in hydrothermal liquefaction of biomass. Renewable and Sustainable Energy Reviews 2011, $15,(3), 1615-1624$.

9. Lehmann, J.; Gaunt, J.; Rondon, M., Bio-char sequestration in terrestrial ecosystems-a review. Mitigation and adaptation strategies for global change 2006, 11, (2), 395-419.

10. Cheng, C.-H.; Lehmann, J.; Thies, J. E.; Burton, S. D., Stability of black carbon in soils across a climatic gradient. Journal of Geophysical Research 2008, 113, (G2), G02027.

11. Nguyen, B. T.; Lehmann, J.; Kinyangi, J.; Smernik, R.; Riha, S. J.; Engelhard, M. H., Long-term black carbon dynamics in cultivated soil. Biogeochemistry 2009, 92, (1-2), 163-176.

12. Laird, D.; Fleming, P.; Wang, B.; Horton, R.; Karlen, D., Biochar impact on nutrient leaching from a Midwestern agricultural soil. Geoderma 2010, 158, (3), 436-442.

13. Keiluweit, M.; Nico, P. S.; Johnson, M. G.; Kleber, M., Dynamic molecular structure of plant biomass-derived black carbon (biochar). Environmental Science \& Technology 2010, 44, (4), 1247-1253. 
14. Knicker, H., How does fire affect the nature and stability of soil organic nitrogen and carbon? A review. Biogeochemistry 2007, 85, (1), 91-118.

15. Elmquist, M.; Cornelissen, G.; Kukulska, Z.; Gustafsson, Ö., Distinct oxidative stabilities of char versus soot black carbon: Implications for quantification and environmental recalcitrance. Global Biogeochemical Cycles 2006, 20, (2).

16. Thangalazhy-Gopakumar, S.; Adhikari, S.; Ravindran, H.; Gupta, R. B.; Fasina, O.; Tu, M.; Fernando, S. D., Physiochemical properties of bio-oil produced at various temperatures from pine wood using an auger reactor. Bioresource Technology 2010, 101, (21), 8389-8395.

17. Regmi, P.; Garcia Moscoso, J. L.; Kumar, S.; Cao, X.; Mao, J.; Schafran, G., Removal of copper and cadmium from aqueous solution using switchgrass biochar produced via hydrothermal carbonization process. Journal of environmental management 2012, 109, 61-69.

18. Lee, J. W.; Kidder, M.; Evans, B. R.; Paik, S.; Buchanan Iii, A.; Garten, C. T.; Brown, R. C., Characterization of biochars produced from cornstovers for soil amendment. Environmental science \& technology 2010, 44, (20), 7970-7974.

19. Skjemstad, J. O.; Gillman, G. P.; Massis, A.; Spouncer, L. R., Measurement of Cation Exchange Capacity of Organic-Matter Fractions from Soils using a Modified Compulsive Exchange Method. Communications in Soil Science and Plant Analysis 2008, 39, (5-6), 926-937.

20. Arami-Niya, A.; Abnisa, F.; Sahfeeyan, M. S.; Daud, W. W.; Sahu, J. N., Optimization of synthesis and characterization of palm shell-based bio-char as a by-product of bio-oil production process. BioResources 2011, 7, (1), 0246-0264.

21. Demirbas, A., Effects of temperature and particle size on bio-char yield from pyrolysis of agricultural residues. Journal of Analytical and Applied Pyrolysis 2004, 72, (2), 243-248.

22. Berge, N. D.; Ro, K. S.; Mao, J.; Flora, J. R. V.; Chappell, M. A.; Bae, S., Hydrothermal Carbonization of Municipal Waste Streams. Environmental Science \& Technology 2011, 45, (13), 5696-5703.

23. Shafizadeh, F., Introduction to pyrolysis of biomass. Journal of Analytical and Applied Pyrolysis 1982, 3, (4), 283-305.

24. Toor, S. S.; Rosendahl, L.; Rudolf, A., Hydrothermal liquefaction of biomass: A review of subcritical water technologies. Energy 2011, 36, (5), 2328-2342.

25. Pradhan, B.K. and N.K. Sandle, Effect of different oxidizing agent treatments on the surface properties of activated carbons. Carbon, 1999. 37(8): p. 1323-1332.

26. Wang, S.-H. and P.R. Griffiths, Resolution enhancement of diffuse reflectance i.r. spectra of coals by Fourier self-deconvolution: 1. C-H stretching and bending modes. Fuel, 1985. 64(2): p. 229-236.

27. Spokas, K. A., Review of the stability of biochar in soils: predictability of O: C molar ratios. Carbon Management 2010, 1, (2), 289-303. 
28. Qiu, Y.; Zheng, Z.; Zhou, Z.; Sheng, G. D., Effectiveness and mechanisms of dye adsorption on a straw-based biochar. Bioresource Technology 2009, 100, (21), 53485351.

29. Hossain, M. K.; Strezov, V.; Chan, K. Y.; Ziolkowski, A.; Nelson, P. F., Influence of pyrolysis temperature on production and nutrient properties of wastewater sludge biochar. Journal of Environmental Management 2011, 92, (1), 223-228. 
FT-IR of Hydrothermal and Pyrolysis Converted Biochars

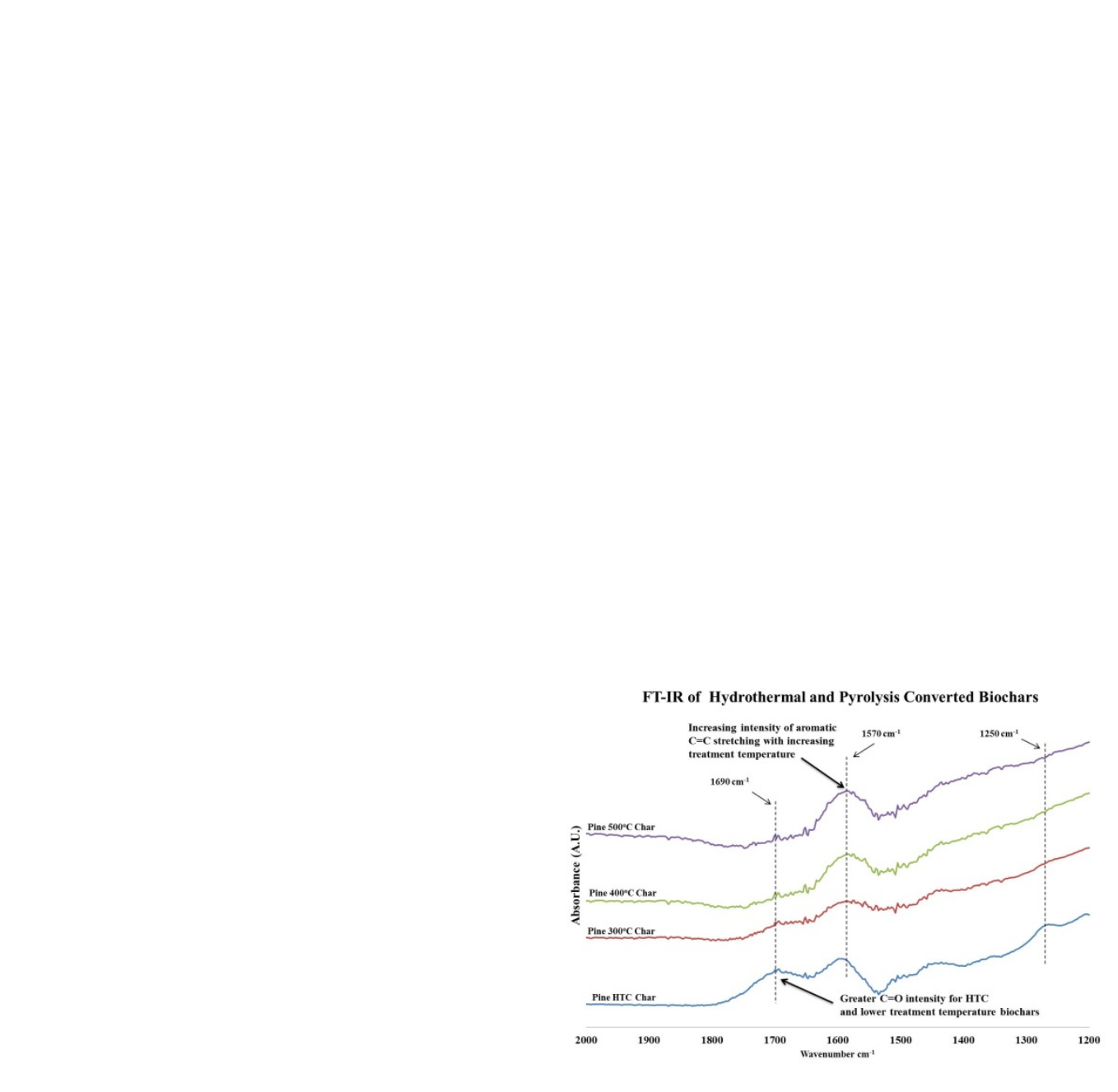

Graphical Abstracts

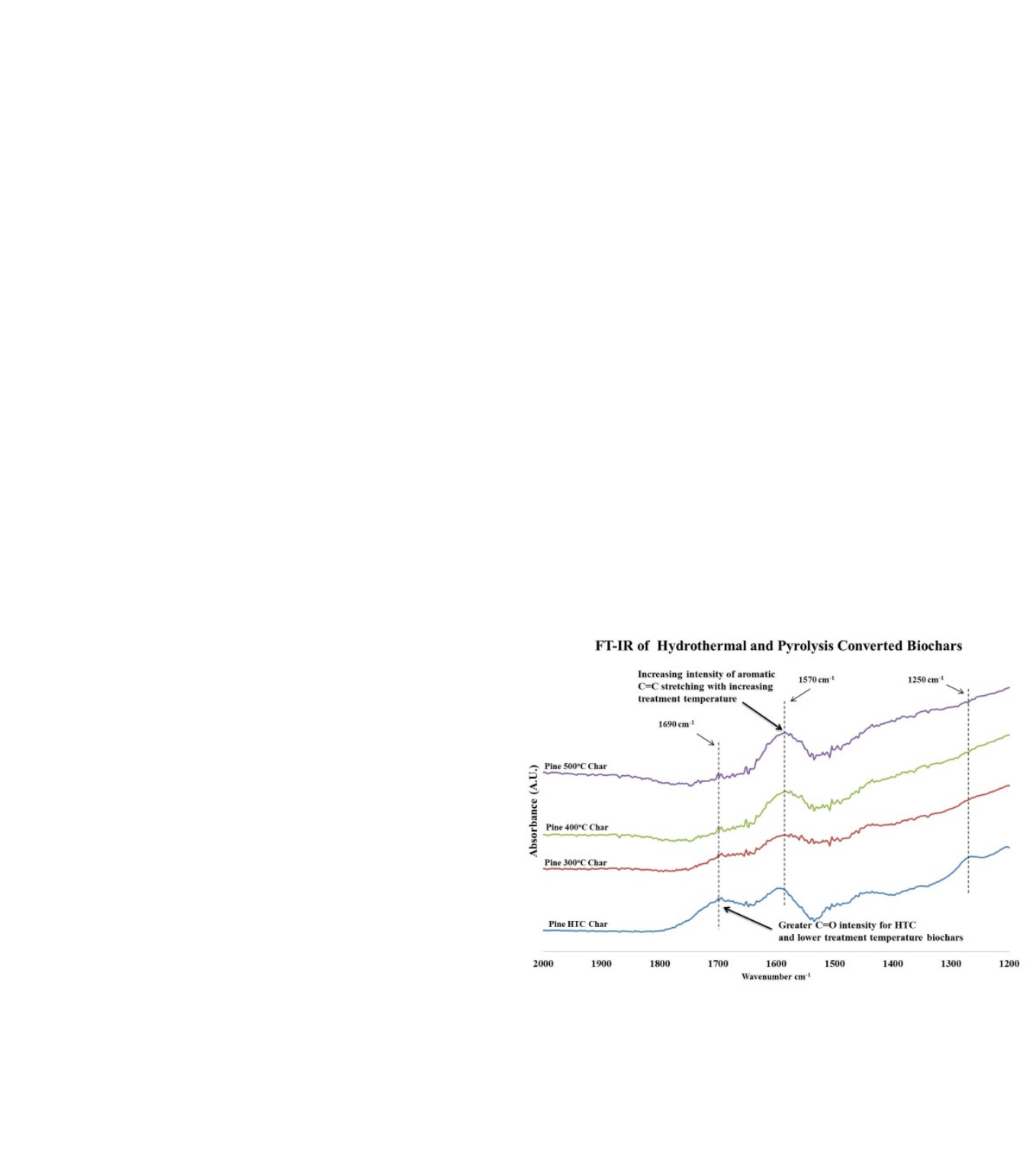

.

要

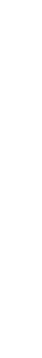

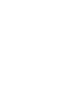
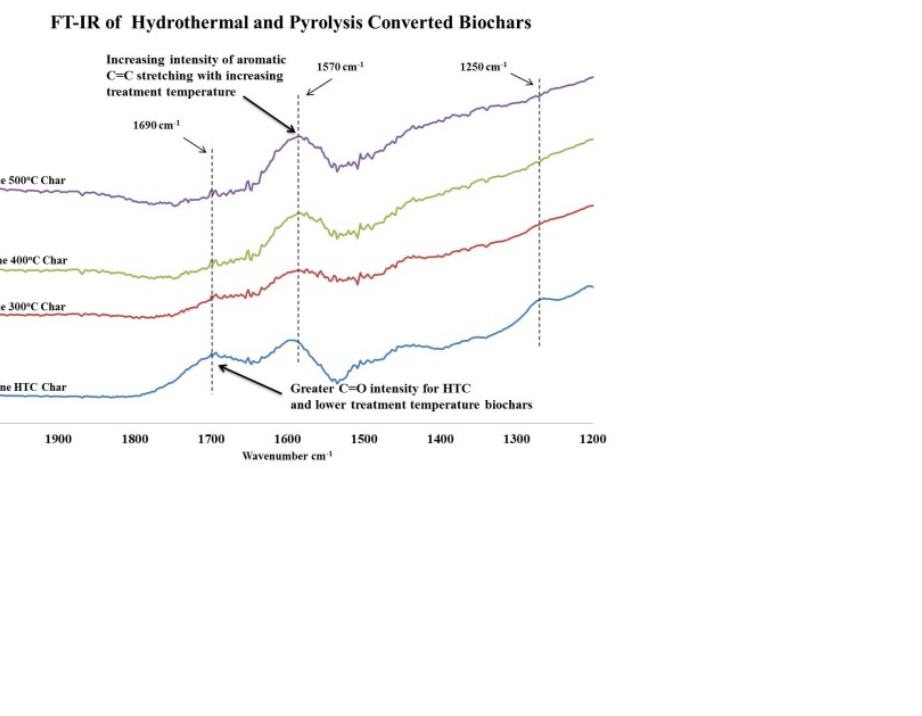

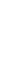

